\title{
Fungal Rhinosinusitis in Delhi-National Capital Region
}

\author{
Sunil Garg, Prafulla Songara, BL Sherwal, Shilpi Agarwal, Partha Rakshit, Sunil Kumar
}

\begin{abstract}
Background and objective: During past decades, fungal rhinosinusitis (FRS) has been diagnosed more frequently. Knowing the fungal flora and its prevalence in chronic rhinosinusitis (CRS) patients will allow a better understanding of this disease, diagnosis and treatment. We studied the prevalence of fungus in CRS patients in Delhi-NCR (National Capital Region) in a tertiary care hospital.
\end{abstract}

Materials and methods: In this prospective study, a total of 180 patients having CRS were enrolled in which functional endoscopic sinus surgery was done. In 173 (96.1\%) patients, polyps/tissue/mass were collected during surgery. In seven $(3.9 \%)$ cases, sinus secretions were obtained. All the collected samples were sent for microbiology and pathology examination. Diagnosis of FRS was confirmed by direct mycological (10\% $\mathrm{KOH})$ and/or culture and/or pathology analysis.

Results: Forty-eight cases were positive for fungus, out of these 180 patients of CRS. In patients of FRS, the most common presentation was nasal blockage followed by facial pain and facial fullness. The prevalence of FRS was found to be $26.6 \%$ in CRS and most common fungal pathogen isolated was Aspergillus flavus.

Conclusion: Delhi-NCR region falls under a moderate prevalence area for fungal infection in CRS patients as compared to other regions in India. Majority of cases were isolated in summer months, the dry and hot climate of the DelhiNCR may be responsible for such prevalence.

Keywords: Aspergillus, FRS, Prevalence, R hizopus.

How to cite this article: Garg S, Songara P, Sherwal BL, Agarwal $S, R$ akshit $P$, Kumar S. Fungal R hinosinusitis in DelhiNational Capital Region. Clin Rhinol An Int J 2013;6(1): 28-31.

\section{Source of support: Nil}

\section{Conflict of interest: None declared}

\section{INTRODUCTION}

India is a vast country with more than a billion people, spread over an area of 3.3 thousand million square kilometers. ${ }^{1,2}$ Geographical and environmental conditions in different parts of the country vary. Located in the tropics and receiving a heavy annual monsoon makes climatic conditions favorable for fungi to grow in major parts of the country. ${ }^{2}$ Fungi are found in air, dust, soil, plants and decaying organic matter. They adhere to dust particles and are inhaled and deposited on the nasal and paranasal sinus mucosa. The warm, moist environment of the upper respiratory tract is an ideal environment for the proliferation of these organisms. ${ }^{3,4}$ However, they are rarely pathogenic because host resistance is high except under favorable growth conditions in highly susceptible individuals.
Although once considered a rare disorder, fungal rhinosinusitis (FRS) has recently gained importance, as an increase in the incidence has been observed during the past decades. This increase in incidence may be due to technological advances in mycology, serology, histopathology and radiology. 5,6 Fungal overgrowth in the nose and sinus is enhanced due to the altered normal bacterial flora by increasing use of broad spectrum antibiotic and topical preparations. ${ }^{7}$ Besides, in the past two decades there is an increase in the use of immunosuppressant drugs, more cases of diabetes mellitus and human immunodeficiency virus (HIV). ${ }^{6}$ The knowledge of type of fungal flora, its prevalence, supplementary tests in patients with chronic rhinosinusitis (CRS) have enabled a better understanding of the disease and increased the awareness of the involved physicians for appropriate diagnosis and treatment of this disease entity. ${ }^{6}$

The fungal agents usually isolated from paranasal sinuses include Aspergillus, Mucor, Histoplasma, Coccidioides, Candida, Fusarium spp, Curvularia spp, Pseudallescheria boydii and Alternaria spp. Aspergillus is the most common fungal pathogen causing fungal sinusitis. ${ }^{8,9}$ The highest mortality rate $(33.3 \%)$ was reported among patients with zygomycotic infection. ${ }^{8}$

The pattern of organisms varies from place to place and depends upon age, habits of the inhabitants, their immune status and other clinical factors. ${ }^{9}$ Treatment in cases of FRS depends on the local preval ence and antifungal sensitivities. The lack of sufficient data relating to actual prevalence of FRS among the clinically suspected patients of CRS in Delhi-NCR (National Capital Region) prompted us to undertake this study. All the cases involved in the study were nonmigrant population of Delhi-NCR .

\section{MATERIALS AND METHODS}

A randomized prospective study was carried out in the Departments of Otorhinolaryngology, M icrobiology and Pathology, Lady Hardinge Medical College, New Delhi, for a period of 3.5 years from November 2008 and A pril 2012. One hundred and eighty patients were randomly selected with CRS fulfilling diagnostic criteria ${ }^{10}$ having age more than 14 years. After recording the complete history and physical examination, computed tomographic (CT) scan and other relevant investigations were carried out for each patient. A II patients underwent functional endoscopic sinus surgery. Nine (5\%) patients were diabetic in this study. 
F ungal R hinosinusitis in Delhi-National Capital Region

A total of 180 samples, $173(96.1 \%)$ polyp/mass and 7 (3.9\%) secretion, were collected from these patients.

One part of the sample was put in a sterile container containing sterile normal saline for mycological and bacteriological examination and the other part was put in $10 \%$ formalin for histopathology. A small amount of specimen was mixed with $10 \%$ potassium hydroxide $(\mathrm{KOH})$ and was examined under magnification of $40 x$ for the presence of fungal elements. The size, morphology and quantity of any fungal elements were noted. Specimen was inoculated on to Sabouraud's dextrose agar (SDA) with antibiotics for fungal culture. SDA was inoculated at $25^{\circ} \mathrm{C}$ and $37^{\circ} \mathrm{C}$ observed for fungal growth daily for 1 week and every week for 3 weeks. Growth, if any, was identified on the basis of rate of growth, color, texture, pigmentation of fungal colony and their morphological features in microscopy. Tissues brought in formalin were processed for histopathological examination (hematoxylin and eosin and periodic-acid Schiff) and the sinus secretions were processed for cytological examination. Diagnosis of FRS was confirmed by direct mycological $(10 \% \mathrm{KOH})$ and/or culture and/or clinical pathology analysis.

\section{RESULTS}

Out of 180 CRS patients, FRS was diagnosed in 28 males and 20 females. The mean age of patients with FRS was 34.3 years (range: $17-63$ years). M aximum 15 cases of FRS were diagnosed in 31 to 40 years of age group. The clinical presentation of patients with FRS is summarized in Table 1. Seasonal variation (monthly isolations) among the FRS cases is shown in Table 2.

A total of 62 isolates were identified from 180 patients of CRS. Out of which 39 were fungal and 23 were bacterial (Table 3). A mong the bacterial isolates, 12 Staphylococcus epidermidis, 5 Escherichia coli and 3 Staphylococcus aureus

\begin{tabular}{lc}
\multicolumn{2}{c}{ Table 1: Distribution of clinical presentation } \\
in patients with FRS
\end{tabular}

\begin{tabular}{lc}
\multicolumn{2}{c}{ Table 2: Monthly isolation of FRS cases } \\
\hline Months & FRS cases (\%) \\
\hline March-J une (Summer) & $24(50)$ \\
July-October (Rainy) & $7(14.6)$ \\
November-February (Winter) & $17(35.4)$ \\
\hline Total & $48(100)$ \\
\hline
\end{tabular}

\begin{tabular}{lc}
\multicolumn{2}{c}{ Table 3: Diagnosis of fungus } \\
\hline Test & No. of cases \\
\hline $\mathrm{KOH}$, culture, histopathology positive & 23 \\
$\mathrm{KOH}$ and culture positive & 16 \\
$\mathrm{KOH}-$ positive only & 9 \\
\hline
\end{tabular}

and Streptococcus pneumoniae each were isolated. A mong fungal isolates, 33 were Aspergillus flavus and six were Rhizopus arrhizus. All Rhizopus arrhizus were isolated from diabetic patients, in whom a history of sudden worsening of CRS existed. Six patients showed mixed infection with Aspergillus flavus and Staphylococcus epidermidis.

\section{DISCUSSION}

A pproximately 300 species of fungi have been documented as having caused diseases in human beings ${ }^{11}$ and $90 \%$ of the infections are attributed to few dozens of species. ${ }^{12} \mathrm{M}$ ost fungi are exogenous; they exist in the soil, water and organic debris. M ost mycoses are caused by littl e fungi that are part of the normal flora, such as candidiasis, or are highly adapted to survive in the human body, such as dermatophytosis. ${ }^{12}$

FRS is a disease that produces significant morbidity or even more fatal outcomes. High morbidity and mortality is seen in patients who develop invasive form of this disease. Since, the incidence of invasive FRS is increasing due to the large number of chronic diseases resulting from aging of the population and/or from pathological situations that require use of immunosuppressant drugs. Early and correct diagnosis combined with proper treatment can reduce the fatality rate associated with this disease. Symptoms are easily overlapping with other diseases and it is difficult for the physician to recognize it. A ssessment and management of these conditions may require the participation of many specialists, including the otorhinolaryngologist, microbiologist and pathologist, providing appropriate diagnosis and treatment. B esides this, the clinical suspicion may be based on the existing prevalence rate of this disease in local community and geographical area. The knowledge of these facts is important in the clinical suspicion and investigative approach of ENT patients with CRS in our daily practice. In our study, we tried to define the prevalence of fungal infection in CRS patients as well as type of clinical presentation of the disease in Delhi-NCR.

We diagnosed FRS on the basis of following criteria: Demonstration of fungal elements by direct microscopical examination $(10 \% \mathrm{~K} \mathrm{OH})$ and/or with isolation of the fungus. This was based on the fact that because they are ubiquitous fungi, contamination of samples by culture can occur easily during the collection or laboratory processing. Considering the simple identification of fungi does not necessarily confirms the pathogenicity, the diagnosis of a mycotic 
infection can only be performed when we analyze the set of data of the culture, surgical findings and results of pathological examination. In our study, out of all 48 cases of FRS, only $23(48 \%)$ samples showed fungal element in histopathology. Similarly Eslamifar et $\mathrm{al}^{13}$ found fungal culture positive in $49(49 \%)$ cases and on histological examination fungal element was seen in $41(41 \%)$ cases. $\mathrm{K}$ arsligil et $\mathrm{al}^{14}$ also showed fungal growth in $55.9 \%$ (33 cases) from patients of CRS while on histopathological examination only $6 \%$ (three cases) showed fungal element.

From 180 patients of CRS, on culture 39 fungus and 23 bacteria were isolated. A mong the culture positive results for fungus, Aspergillus flavus was the commonest causative fungi, isolated in $33(84.61 \%)$ cases. This is in agreement with other studies in India and from outside India.,14-16 Rhizopus arrhizus was isolated in six patients, all of whom were diabetic. In these cases, bony erosion was also seen by CT scan finding suggesting invasive FRS. Panda et al also found, 10 out of 12 Rhizopus arrhizus in diabetic patients. ${ }^{17}$

During the 42 months of our study period, maximum number of FRS ( $50 \%$ patients) was observed during $M$ arch to J une (summer) months. A ccording to $M$ et $M$ onograph N o. Environment M eteorology-01/2010 climate profile of India, by India M eteorological Department, Ministry of Earth Sciences, Govt. of India, the temperatures start to increase all over the country in M arch and by A pril and maximum temperatures rise sharply exceeding $45^{\circ} \mathrm{C}$ by the end of $\mathrm{M}$ ay and early June resulting in harsh summers in the $\mathrm{N}$ orth and $\mathrm{N}$ orth-W est regions of the country. The season is al so characterized by cyclonic storms, which are intense low pressure systems over hundreds to thousands of kilometers associated with surface winds more than 33 knots over the Indian seas viz B ay of B engal and the A rabian Sea. These systems generally move toward a northwesterly direction and some of them recurve to northerly or northeasterly path. Hot and dry winds accompanied with dust winds ('andhi') blow frequently over the plains of northwest India. ${ }^{17}$ During summer, sandstorm disseminate the fungal spores leading to widespread colonization and prolonged exposure to large inocula of spores which probably initiates chronic sinonasal infection, as dry and warm climate appears to be important factor for higher incidence of FRS. Dusty and arid conditions possibly predispose to rhinitis and recurrent sinusitis that facilitates the growth of fungi. Possibly, the dust and frequent sand storms during the summer months contain large numbers of Aspergillus conidia that can easily settle on the injured mucosa of the sinuses. ${ }^{18}$

FRS was diagnosed in all age groups range from 17 to 63 years age. $M$ aximum numbers of cases were found in 31 to 40 years of age group and the mean age was 34.3 years.
Chakrabarti et al ${ }^{19}$ reported younger age groups are more susceptible for FRS. The mean age for fungal nasal polyposis shows that adults who expose to air pollutant and use more antibiotics through their life suffer from the disease. The extremes of age were contributed with underlying disease. However, no particular age group can be considered a risk factor for the development of FRS.

We found the prevalence of FRS in CRS patients in our region is $26.6 \%$. The prevalence rate reported is less as compared to other studies from various parts of India. Chakrabarti et al ${ }^{3}$ from Chandigarh and $V$ enugopal et al ${ }^{20}$ from T amil $\mathrm{N}$ adu reported $42 \%$ and $45 \%$ of prevalence rates respectively. This may be due to different climate conditions like temperature and air relative humidity ${ }^{4}$ playing a role in the pathogenesis of $F R S$, as the presence of a specific fungus in the environment is related with environmental conditions. The significantly higher preval ence rate in some studies has been attributed to improved and novel technique for processing samples for detection of fungi. This varying prevalence in different geographical areas remains unexplained.

\section{CONCLUSION}

In Delhi-NCR, the prevalence of FRS was found to be $26.6 \%$ and most frequently isolated fungus was Asper gillus flavus. Our region falls under a moderate prevalence area after comparing with data from other regions. As highest percentage of cases were isolated in summer months, dry and hot climate of the Delhi-NCR may be responsible for such prevalence. This led us to believe that during summer months high degree of suspicion should be given for FRS in CRS patients.

\section{REFERENCES}

1. Census of India. Office of the census control and registrar general of India. A vailable from: http://www.censusindia.gov.in/ Census_Data_2001/India_at_glance.

2. Chakrabarti $\bar{A}$, Chatterjee SS, Shivaprakash M R. Overview of opportunistic fungal infection in India. Jpn J Med M ycol 2008;49:172-95.

3. Chakrabarti A, Das A, Panda NK. Overview of fungal rhinosinusitis. Indian J Otolaryngol Head Neck Surg 2004;56(4):251-58.

4. Benoliel P. Treatment of sinonasal polyposis by Candida albicans immunotherapy: A propos of 4 cases. Allerg Immunol (Paris) 2001;33(10):388-94.

5. Hope WW, Walsh TJ, Denning DW. Laboratory diagnosis of invasive aspergillosis. L ancet Infect Dis 2005;5:609-22.

6. Dall'I gna C, Palombini BC, A nselmi F,A raujo E, Dall'I gna DP. Fungal rhinosinusitis in patients with chronic sinusal disease. Rev B ras Otorhinolaryngol 2005;71(6):712-20.

7. Shao $P$, Huang $L$, Heueh $P$. Invasive fungal infectionlaboratory diagnosis and antifungal treatment. J Microbiol Immunol Infect 2006 39:178-88. 
8. Jahromii SB, K haksar A A. Paranasal sinus mycosis in suspected fungal sinusitis. Iran J Clin Infect D is 2006;1(1):25-29.

9. Joshi RR, B handary $S, K$ hanal $B$, Singh RK. Fungal maxillary sinusitis: A perspective study in a tertiary care hospital of Eastern Nepal. K athmandu M ed J 2007;5(2):195-98.

10. Lanza DC, Kennedy DW. A dult Rhinosinusitis defined. Otolaryngol Head Neck Surg 1997;117:51-57.

11. Marple BF, Mabry $R L$. The role of fungus in chronic rhinosinusitis. Curr Opin Otolaryngol Head Neck Surg 2002;10:207-12.

12. M itchel TG. O verview of basic medical mycology. O tolaryngol Clin North A m 2000;33:237-49.

13. Eslamifar A, Razzaghi-A byaneh $M$, Vazir-Nezami $M$, Moghadasi $H$, Ramezani A, Shams-Ghahfarokhi $M$, et al. Frequency and identification of fungal strains in patients with chronic rhinosinusitis. Iran J Pathol 2008;3(3):135-39.

14. Karsligil T, M umbuc $S$. M icrobiological evaluation for fungal involvement of the paranasal sinuses in Turkey. J Chinese Clin M ed 2008;3(10):549-53.

15. A bdulrahman A, Enani AM, M ahasin Z, Omran KA. Chronic invasive aspergillosis of the paranasal sinuses in immunocompetent hosts from Saudi A rabia. A m J Trop Med Hyg 2001; 65(1):83-86.

16. Goh B, Singh B, M ohamed RI, Sabiha P, Samad A S. Preval ence of allergic fungal sinusitis in refractory chronic rhinosinusitis in adult Malaysians. Otolaryngology Head Neck Surg 2005;133(1):27-31.

17. Climate profile of India. India M eteorological Department. A vailable from: http://www.imd.gov.in/doc/climate_profile.

18. Panda NK, Sharma SC, Chakrabarti A, M ann SB. Paranasal sinus mycoses in N orth India. M ycoses 1998;41:281-86.

19. Chakarbarti A, Sharma SC, Chandler J. Epidemiology and pathogenesis of paranasal sinus mycoses. Otolaryngology. Head Neck Surg 1992; 107:745-50.
20. Venugopal PV, Venugopal TV, A bakrishnan KB. Chronic fungal sinusitis in Tamil $\mathrm{Nadu}$, India. J Med Mycol 2008;18(4):216-23.

\section{ABOUT THE AUTHORS}

\section{Sunil Garg (Corresponding Author)}

Senior R esident, D epartment of ENT, Otorhinolaryngology, Head and Neck Surgery, Lady Hardinge M edical College, N ew Delhi-110001 India, e-mail: dr.sunilgarg07@gmail.com

\section{Prafulla Songara}

Senior Resident, D epartment of M icrobiology, L ady Hardinge M edical College, New Delhi, India

\section{BL Sherwal}

Professor, Department of M icrobiology, Lady Hardinge M edical College, New Delhi, India

\section{Shilpi Agarwal}

Professor, D epartment of Pathology, L ady Hardinge M edical College New Delhi, India

\section{Partha Rakshit}

A ssistant Director, Department of M icrobiology, Central Research Institute, Himachal Pardesh, India

\section{Sunil Kumar}

Professor, Department of ENT, Lady Hardinge Medical College New Delhi, India 